Analysis

\title{
Biocapacity supply and demand in Northwestern China: A spatial appraisal of sustainability
}

\author{
Dongxia Yue ${ }^{\mathrm{a}, 1}$, Xiaofeng $\mathrm{Xu}^{\mathrm{b}, 1}$, Cang Hui ${ }^{\mathrm{c}}$, Youcai Xiong ${ }^{\mathrm{d}}$, Xuemei Han ${ }^{\mathrm{e}}$, Jinhui Ma ${ }^{\mathrm{a}, *}$ \\ a MOE Key Laboratory of Western China's Environmental Systems, Lanzhou University, Lanzhou, Gansu 730000, China \\ b School of Management, Lanzhou University, Lanzhou, Gansu 730000, China \\ c Centre for Invasion Biology, Department of Botany \&' Zoology, Stellenbosch University, Private Bag X1, Matieland 7602, South Africa \\ ' Key Laboratory of Arid and Grassland Ecology, Ministry of Education, Lanzhou University, Lanzhou, Gansu 730000, China \\ e School of Forestry and Environmental Studies, Yale University, New Haven, CT 06511, USA
}

\section{A R T I C L E I N F O}

\section{Article history:}

Received 21 June 2010

Received in revised form 17 December 2010

Accepted 21 December 2010

Available online 1 February 2011

\section{Keywords:}

Biocapacity

Ecological footprint

Remote sensing

Spatial heterogeneity

Northwestern China

\begin{abstract}
A B S T R A C T
Integrating spatial analysis with the supply and demand of biocapacity is critical for the sustainable development of regional eco-economic systems. Previous studies have focused on the temporal analysis of biocapacity at broad geographical scales, but lacked the systematic spatial realization at fine scales. An improvement is proposed of this conventional methodology of the ecological footprint by incorporating landuse data derived from high-resolution remote-sensing images into the calculation of biocapacity supply at regional, provincial and county levels in Northwestern China in 2000. The spatial heterogeneity and its effect on the biocapacity supply were systematically revealed for this region. First, the biocapacity supply declined from the east (the Guanzhong Basin and the Loess Plateau) to the middle (the Qaidam Basin and the Turpan Basin), and turned to rise from the middle to the west (the northwest of the Xinjiang Uygur Autonomy). Second, although the gap between biocapacity supply and demand resulted in a small ecological deficit at the regional level, a large ecological deficit was observed at the provincial and county levels, highlighting an unsustainable situation for some of the sub-regions. Importantly, a power law relationship was unveiled between the biocapacity supply and population density, suggesting that (i) the biocapacity supply as a critical indicator could reflect the intensity of human exploitation on local biophysical resources and (ii) humans tend to have a preference to inhabit those areas with high biological productivity. These results provide opportunities to enhance policy development by central and local governments as part of the long-term Great Western Development Strategy of China.
\end{abstract}

(c) 2010 Elsevier B.V. All rights reserved.

\section{Introduction}

Sustainable development is a desired policy goal worldwide (WCED, 1987). Within this context, the concept of biocapacity serves not only as a support for social development and human wellbeing (Carey, 1993; Scoones, 1993; Sagoff, 1995; Gao, 2001), but also sets an ecological limit for human activities (Rees, 2006), with its concept rooted in the carrying capacity of the logistic population growth equation (Seidl and Tisdell, 1999). The concept of carrying capacity has evolved through several stages, from population carrying capacity to resource and environmental carrying capacity, on to biocapacity in ecological economics. In the ecological footprint (EF) methodology developed by Rees (1992) and Wackernagel and Rees (1996), biocapacity is defined (Rees, 1992; Rees and Wackernagel, 1994) as the carrying capacity of ecosystems to produce useful biological materials and to absorb waste materials generated by humans. As

\footnotetext{
* Corresponding author. Tel./fax: +86 9318912343.

E-mail address: majh@lzu.edu.cn (J. Ma).

1 The first two authors contribute equally.
}

such, biocapacity stands for a more holistic appraisal of regional ecosystems than other measures (Arrow et al., 1995; Gao, 2001; Yue et al., 2006).

A number of methods have been proposed to quantitatively estimate biocapacity, including net primary productivity (NPP; Lieth, 1972), ecological footprint (EF; Rees, 1992), emergy (Odum, 1996) and a synthetic evaluation based on the analytical hierarchy process (Gao, 2001). Among them, the EF methodology has attracted much attention over the last decade due to its ease of use and compatibility with the data formats from social and economic surveys (e.g., Wackernagel and Rees, 1996; Levett, 1998; van den Bergh and Verbruggen, 1999; Costanza, 2000; Opschoor, 2000; Lenzen and Murray, 2001; Haberl et al., 2001; Senbel et al., 2003; Yue et al., 2006; White, 2007; Kitzes et al., 2009; Kissinger and Rees, 2009, 2010), and has thus been widely applied at the regional level (e.g. ,McDonald and Patterson, 2004; Chang and Xiong, 2005; Yue et al., 2006; Kissinger et al., 2007), national level (e.g., Haberl et al., 2001; Lenzen and Murray, 2001; Wackernagel et al., 1999; Wackernagel and Galli, 2007; Bicknell et al., 1998; van Vuuren and Smeets, 2000) and global level (e.g., White, 2007; WWF, 2008). As a young and still developing methodology, the 
EF calculation requires more integrating design to represent the relationship between humanity and nature (Rees, 2000; Wackernagel and Yount, 2002; WWF, 2006), and the inclusion of spatial structure is thought to meet this requirement, especially with the introduction of the geographic information system (GIS) into the solution (e.g., Wood, 2003; Chang and Xiong, 2005; Yue et al., 2006).

In a standard EF study, biocapacity is often measured by the available area of biologically productive land and water based on data reported in national or regional statistics. A drawback of this methodology is that data often excludes the spatial information of the EF and biocapacity as well as the spatial heterogeneity of natural capital and land use (Erb, 2004). Furthermore, national and regional statistics are often reported at a coarse resolution for political use and may not be applicable for biocapacity assessment at the level of precision required to inform policy making at regional scales (Mayer, 2008; Chang and Xiong, 2005). Concerns over the effect of these blind spots on the spatial assessment of sustainability continue to battle researchers (van den Bergh and Verbruggen, 1999; Opschoor, 2000; Templet, 2000), and an improved methodology that can address these shortfalls is needed (Luck et al., 2001; Jenerette et al., 2006; Kitzes et al., 2009). In this regard, GIS models have been strongly recommended for their ability to provide better estimates than spatially implicit estimates (Kitzes et al., 2009). Therefore, it is possible to use remote-sensing data of land use combined with the spatial analysis techniques in GIS to calculate a spatially explicit biocapacity at both coarse and fine scales, as demonstrated by a few case studies (e.g., Chang and Xiong, 2005; Heumann and Moran, 2006; Moran et al., 2009).

Since 1999, the Great Western Development Strategy of China has been a national policy to ease the national imbalance of economic and social developments, with special focus on the less developed western regions. The implementation of this strategy, together with the ensuing population and economic growth in the region, has caused the impact of human activities on water and land resources to escalate, posing threats not only to the ecosystem, but also to national security. We therefore select Northwestern China (NWC) as a study area for a quantitative and spatial appraisal of the supply and demand of biocapacity. Specifically, we present a quantitative assessment of the spatially explicit biocapacity demand and supply of NWC (covering some $3 \times 10^{6} \mathrm{~km}^{2}$, and containing 5 provinces and 358 counties) at multiple spatial scales, using a combination of techniques from the EF methodology and the spatial analysis in GIS. A series of indices of biocapacity are developed to reflect the integrated status of ecological sustainability at different spatial scales. This study thus refines the current EF methodology and emphasizes the spatial heterogeneity of the regional biocapacity.

\section{Method}

\subsection{Study Area}

Northwestern China (NWC) is an arid to semi-arid region lying at $70^{\circ} 02^{\prime}-110^{\circ} 48^{\prime} \mathrm{E}$ and $31^{\circ} 47^{\prime}-45^{\circ} 22^{\prime} \mathrm{N}$ (Fig. 1A), bordered by Mongolia, Russia and a few Central Asian countries. It comprises the provinces of Shaanxi, Gansu and Qinghai, as well as the autonomous regions of Ningxia Hui and Xinjiang Uyghur, covering a total area of $3,094,730 \mathrm{~km}^{2}$. It accounts for $32 \%$ of China's domestic territory, yet only $7.1 \%$ of the whole country's population (89 million according to the fifth Chinese census in 2001), with a third of the population from ethnic minorities (mainly Mongol, Hui, Uygur, Tibetan and Kazakh). The region supports the lowest population density in China, 28.9 persons per $\mathrm{km}^{2}$. It encompasses a vast expanse of territory including the northern Qinghai-Tibetan Plateau, the middle-western Loess Plateau and the Central Asia Tianshan Mountains. Water resources are scarce and extremely unevenly distributed in the region. Annual precipitation for most of the area is below $400 \mathrm{~mm}$, with the exception of the southern parts of the provinces of Shaanxi and Gansu (>800 mm). The main ecotype is desert and steppe, with a small coverage of forests (9.4\% in Gansu, 4.9\% in Ningxia, 1.7\% in Xinjiang, 0.4\% in Qinghai, and $24.1 \%$ in Shaanxi). Soil erosion is severe due to both wind and water weathering.

\subsection{Ecological Footprint Methodology}

The ecological footprint (eco-footprint) for a particular population is defined as the total "area of productive land and water ecosystems required to produce the resources that the population consumes and assimilate the wastes that the population produces, wherever on Earth that land and water may be located" (Rees, 1992). Rees and Wackernagel (1994) also refers to eco-footprint as the 'appropriated carrying capacity' (or human demand on nature) and biocapacity as the locally available carrying capacity of the ecosystem. Therefore, the two indicators, eco-footprint and biocapacity, represent the demand and supply of biocapacity. A comprehensive assessment of regional eco-footprint together with an estimate of regionally-available biocapacity gives a good indication of the sustainability of regional social-ecological systems (Wackernagel and Silverstein, 2000; Haberl et al., 2001; Monfreda et al., 2004; WWF, 2004). The 'ecological surplus' or 'deficit' is defined as the difference between the available biocapacity and the eco-footprint (Wackernagel et al., 2002). This specifies whether a regional population is potentially self-sufficient or is at least partially reliant on imported biocapacity (Haberl et al., 2001).

Given the continuous increase of ecological pressure on the closed system of our planet, the management of human eco-footprint (demand) relative to biocapacity (supply) becomes one of the most important issues of the century (Kitzes et al., 2008). The EF methodology often uses "global hectares" (gha) as a standard unit that represents biologically productive areas with the world average productivity to quantify the eco-footprint and biocapacity, weighing by the equivalence, yield, and fossil-energy conversion factors (Wackernagel et al., 1999; WWF, 2004). The equivalence factor and the yield factor are used to convert the actual area sizes (in hectares) of different land types into their equivalents in global hectares. The fossil-energy conversion factor is the global average energy footprints of various energy categories, and is often used to convert human energy consumption to eco-footprint (Wackernagel et al., 1999). In this study, biologically productive areas are categorized into six main types (cropland, grazing land, fishing ground, forest, built-up area and carbon-uptake land) (Wackernagel et al., 1999; Hansen et al., 2000) and calculated using a weighted sum (in global hectare; Table 1; Fig. 1B). Furthermore, although barren ground (including exposed soil, sand, rocks, snow or ice with less than $10 \%$ vegetation cover throughout the year) occupies a large area of approximately $47.8 \%$ of Northwestern China (Hansen et al., 2000), we simply considered the biocapacity of barren ground to be zero in the calculation due to its extremely low productivity.

In addition to the three most frequently used EF measures - percapita eco-footprint, per-capita biocapacity and per-capita ecological budget (surplus or deficit), three further indices were determined per-unit-area biocapacity, eco-footprint per unit GDP and biocapacity pressure index. The per-unit-area biocapacity is simply the ratio of regional biocapacity to regional land area and reflects not only the efficiency of local land utilization, but also the status of environmental conditions and the productive potential of the land. The eco-footprint per unit GDP is the ratio of regional eco-footprint to local GDP and reflects the efficiency and development level of the local economy. The biocapacity pressure index is the regional eco-footprint to biocapacity ratio and reflects the pressure posed by the human population on the local ecosystem. If the biocapacity pressure index is greater than one, the population is in ecological overshoot, indicating that regional development is not ecologically self-sustaining. If the 

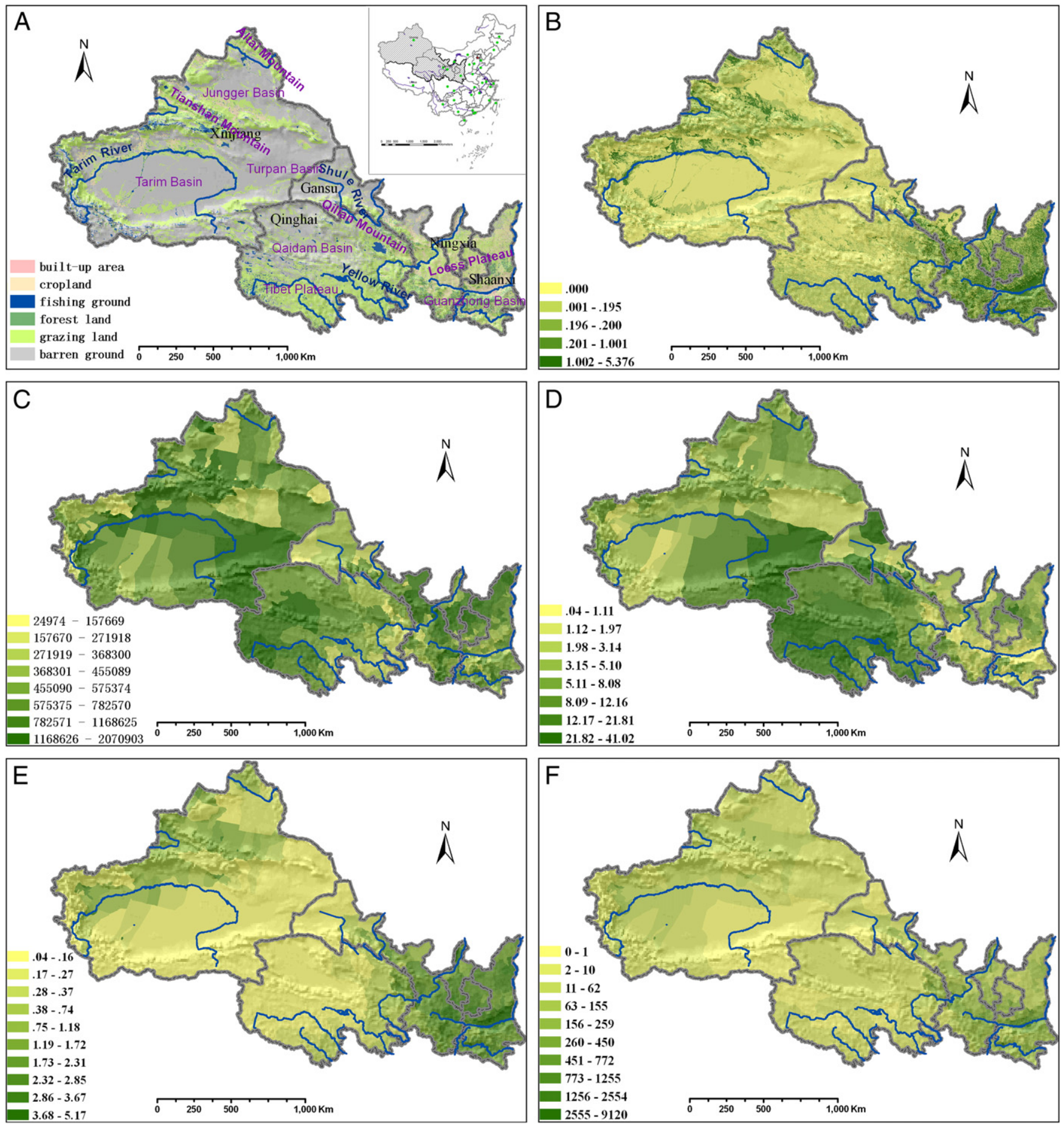

Fig. 1. Maps of land-use (A), the absolute value of biocapacity (B), total biocapacity of all counties (C), per-capita biocapacity of all counties (D), per-unit-area biocapacity of all counties (E) and the population density of all counties (F) in Northwestern China in 2000

Table 1

The definitions of the six types of biologically productive areas.

\begin{tabular}{ll}
\hline Biologically productive area & Meaning \\
\hline Cropland & For crop production \\
Grazing land & For raising livestock \\
Fishing ground & For aquatic product \\
Forest & For the production of timber products \\
Carbon-uptake land & For sequestering $\mathrm{CO}_{2}$, or for generating \\
& other forms of energy. \\
Built-up area & For houses, buildings and factories, etc. \\
\hline
\end{tabular}

biocapacity pressure index is less than one, the region is potentially self sufficient.

\subsection{Data Analysis and Calculation}

\subsubsection{Demand on Biocapacity (Eco-footprint)}

The eco-footprint at different scales in NWC was calculated using social statistics in 2000 by employing the EF methodology (Wackernagel et al., 1999; Yue et al., 2006). All social statistics were taken from provincial and national yearbooks in 2001 (China Statistics Press) and the FAO Production Yearbook in 2001 (www.fao.org). The import and 
export information of NWC included two sections: trade with other nations and within China. Data for the first section were taken from the above yearbooks. However, data for the second section was not available. Instead, we calculated the eco-footprint based on consumption per person to avoid the use of import and export data within China. The equivalency and yield factors were both calculated according to the average yield of the 5 provinces and the global level in 2000. The equivalency and yield factors for the barren ground were regarded as zero. The conversion factor of fossil-energy footprints was kept constant across all areas as suggested by Wackernagel et al. (1999).

\subsubsection{Biocapacity Supply}

Biocapacity at different scales in NWC was calculated using the spatial data of land use in 2000 as a base layer for the GIS analysis (Wackernagel et al., 1999). The spatial data of land use/cover and the administration map of NWC were provided by the Environmental and Ecological Science Data Center for West China (WestDC), and the vector map of land-use was derived from Landsat TM images (2000year), assisted by field surveys, with a nominal resolution of $30 \mathrm{~m}$ at the scale of 1:100,000, the same resolution as the administration map. By comparing the data from the Landsat TM image with the field survey, the overall accuracy of classification (the ratio of the number of correctly identified localities to total reference number) was greater than 90\% (Wang et al., 2001; Zhang et al., 2002), suggesting a robust input for the calculation of biocapacity in NWC (Liu et al., 2002).

Analyses were made at three administrative scales (including the entire NWC, province and county) using ArcGIS 9.2 (ESRI). The map of biocapacity in NWC was developed using a new attribute table in ArcGIS of the product of equivalency and yield factors at the land use unit (the absolute value of biocapacity supply). The county and provincial level administrative maps were then overlaid on the biocapacity map for calculating the biocapacity at these two levels. Based on the absolute value of biocapacity and the social statistics data for all counties, we then produced the maps of per-unit-area and per-capita biocapacity at county- and provincial-level. Human population density of all counties was also reported for comparison. It was assumed that $12 \%$ of the biologically productive area of biocapacity should be preserved for biodiversity protection (WCED, 1987; Wackernagel and Rees, 1996) and this area was deducted for all biologically productive areas types.

\section{Results}

As shown in Table 2, the total biocapacity in NWC was $1.445 \times$ $10^{8}$ gha, in contrast to the total eco-footprint of $1.453 \times 10^{8}$ gha, a slight $0.5 \%$ ecological deficit. At the provincial level, Shaanxi and Xinjiang were in ecological overshoot, with ecological deficits of $17 \%$ and 9.7\%, whereas Gansu, Ningxia and Qinghai were self-sustainable, with ecological surpluses of $15 \%, 17.3 \%$ and $20.8 \%$, respectively. The per-unit-area biocapacity of Shaanxi and Ningxia was higher than that of Xinjiang, Qinghai and Gansu, indicating a higher efficiency of land utilization in Shaanxi and Ningxia. However, Shaanxi had the highest biocapacity pressure index, followed by Xinjiang. In contrast, Qinghai had the highest eco-footprint per unit GDP, suggesting low efficiency of the local economics.

The biocapacity was unevenly distributed across vast heterogeneous landscapes (Fig. 1B), forming two high supply regions divided by the $100^{\circ} \mathrm{E}$ longitude. The east region lies around the Guanzhong Basin in Shaanxi and eastern Gansu; the west region lies in between the Tianshan Mountains and Tarim Basin in Xinjiang. In general, the biocapacity gradually decreased from the eastern to middle region and increased from the middle to western region, with the lowest region lying in between the Qaidam and Turpan Basins. Overall, the biocapacity was relatively high in the western Loess Plateau, the north-eastern Tibet Plateau, Qilian Mountains, Tianshan Mountains and Altai Mountains. The biocapacity was highest in Guanzhong Basin, Yinchuan Basin and many oases of the arid region, whereas the biocapacity supply was low in the desert basins of Tarim, Jungger, Qaidam and Turpan. In addition, the spatial distribution of biocapacity supply was smoother in the east (e.g., on the Loess Plateau) than in the west (e.g., in Xinjiang), reflecting the geographical characteristics of the terrain.

The spatial distribution of the total biocapacity at county level was also uneven and biased by the county size (Fig. 1C), with larger counties having higher biocapacity. The per-capita biocapacity at the county level was low in the Guanzhong Basin in the middle of Shaanxi, Yinchuan basin in northern Ningxia, middle and eastern Gansu and the Hexi Corridor, the west and southeast part of Xinjiang and the middle of the Tianshan Mountains (Fig. 1D), especially around the cities. The per-unit-area biocapacity around cities was high mainly in the east part of the region (Fig. 1E), in contrast to the per-capita biocapacity. Overall, the spatial distribution of per-unit-area biocapacity was similar to that of the human population density at county scale (Fig. 1E and F). Further analysis showed a power law relationship between the population density and per-unit-area biocapacity (with a saturation level of $5 \mathrm{gha} / \mathrm{ha}$; Fig. 2). The power law relationships of Shaanxi and Ningxia followed a similar form, but both had much shallower slopes than that of the other three provinces (as well as for the entire NWC), suggesting a higher land-use efficiency in Shaanxi and Ningxia.

The partition of the biocapacity indicated that the six major categories of biologically productive area contributed differently in each province (Fig. 3). The biocapacity of cropland accounted for more than $80 \%$ of the total in Ningxia, Shaanxi and Gansu, and was slightly lower in Xinjiang (66\%), with the lowest contribution of cropland in Qinghai (28.2\%). It suggests that there was a large potential to increase the biocapacity by increasing the agricultural yield on the Qinghai-Tibetan Plateau. The contribution of fishing ground to the biocapacity was extremely low $(<4 \%)$, showing that water was scarce in NWC and a limiting factor for increasing biocapacity in this sector. Grazing land contributed a significant portion to the biocapacity in Qinghai (47\%) and Xinjiang (19.4\%), reflecting the nomadic cultural

Table 2

The demographic information, the eco-footprint and biocapacity of the five provinces in Northwestern China in 2000.

\begin{tabular}{|c|c|c|c|c|c|c|}
\hline & Shaanxi & Gansu & Qinghai & Ningxia & Xinjiang & NW China \\
\hline Population density (persons/ha) & 1.769 & 0.631 & 0.072 & 1.098 & 0.113 & 0.302 \\
\hline Land per person (ha per capita) & 0.565 & 1.585 & 13.885 & 0.911 & 8.862 & 3.308 \\
\hline Biocapacity $\left(10^{8}\right.$ gha $)$ & 0.406 & 0.384 & 0.137 & 0.096 & 0.423 & 1.445 \\
\hline Eco-footprint ( $\left.10^{8} \mathrm{gha}\right)$ & 0.475 & 0.326 & 0.109 & 0.079 & 0.464 & 1.453 \\
\hline Per-capita biocapacity (gha per capita) & 1.113 & 1.504 & 2.657 & 1.726 & 2.292 & 1.586 \\
\hline Per-capita eco-footprint (gha per capita) & 1.303 & 1.278 & 2.103 & 1.427 & 2.514 & 1.594 \\
\hline Per-capita ecological budget (gha per capita) & -0.190 & 0.226 & 0.554 & 0.299 & -0.222 & -0.008 \\
\hline Biocapacity pressure index & 1.170 & 0.850 & 0.790 & 0.830 & 1.100 & 1.005 \\
\hline Per-unit-area biocapacity (gha/ha) & 1.969 & 0.948 & 0.191 & 1.895 & 0.259 & 0.480 \\
\hline Eco-footprint per unit GDP (gha per $10^{4}$ Yuan) & 2.859 & 3.316 & 4.121 & 2.979 & 3.402 & 3.114 \\
\hline
\end{tabular}




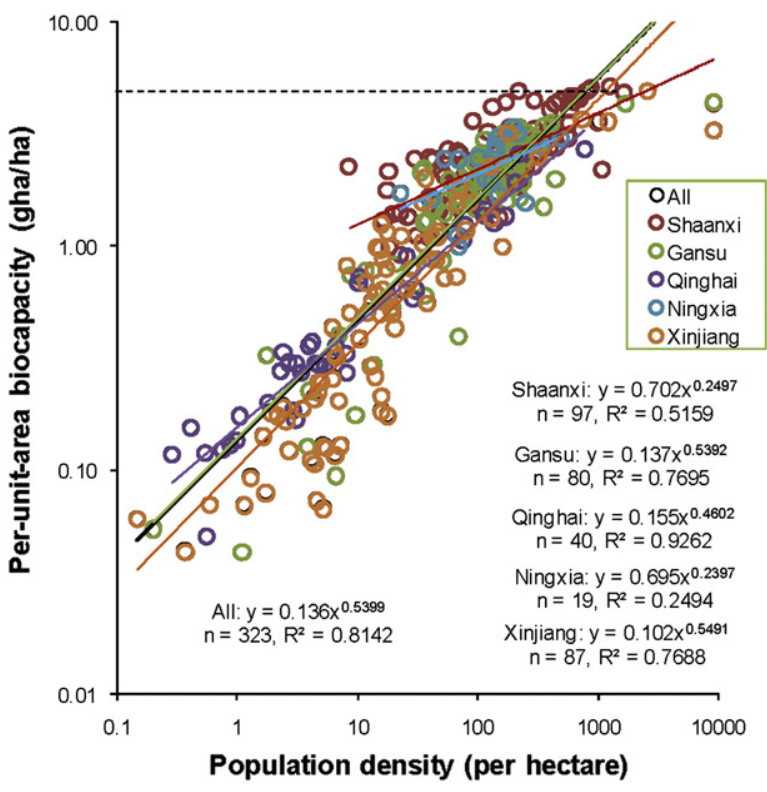

Fig. 2. The relationship between per-unit-area biocapacity and population density in the five provinces of Northwestern China in 2000. Each point indicates a county. The dashed line indicate the saturation level of the per-unit-area biocapacity at $5 \mathrm{gha} / \mathrm{ha}$.

backgrounds of the Tibetan and Uygur peoples, in contrast to the crop planting culture in Shaanxi, Ningxia and Gansu.

\section{Discussion}

Our results indicated a $76.2 \%$ greater biocapacity per capita in NWC than in China as a whole, but the region only has about $75.9 \%$ of the per-capita eco-footprint in China (WWF, 2008). However, the biocapacity per capita and the eco-footprint per capita in NWC are $24.5 \%$ and $41 \%$ lower than the world level, respectively (WWF, 2008), a typical feature of underdeveloped region. Using the calculated pressure index of 1.005 for this region (Table 2), the pressure index for the entire nation can be estimated to be around 2.3, suggesting a very unsustainable development path currently in China. With the increase of regional population, the improvement of living standards, the change of consumption behaviour (the adoption of unsustainable lifestyle), and the growth of a high-risk dependency on trade and extra-territorial land biocapacity (Kissinger and Rees, 2009, 2010), the demand is expected to surpass, or even has already surpassed, the supply of biocapacity in the region. A rapid rise of ecological deficit in

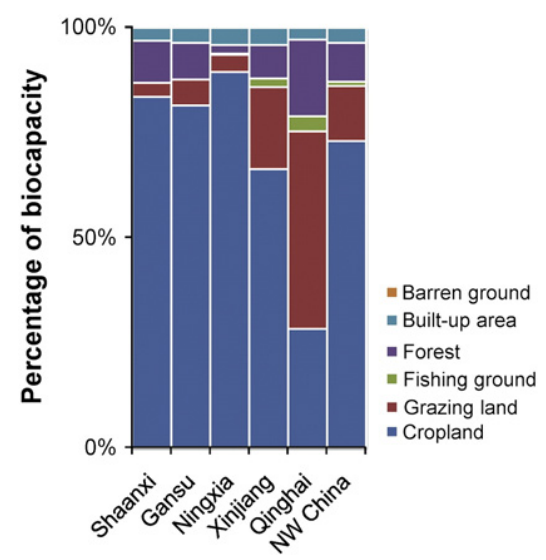

Fig. 3. The percentage of biocapacity of six major categories of biological productive area in Northwestern China in 2000. all provinces of NWC is well on the way, especially with current unprecedented trend of globalization and industrialization in China.

The biocapacity of fishing ground was extremely low and uneven in the region, particularly in Gansu, Xinjiang and Ningxia (see Fig. 3). It suggests that in addition to continuingly encouraging low birth rates and enhancing efficiency of nature resource consumption (especially water resource and fossil energy), local governments could minimize the ecological deficit by (i) constantly improving water resource management, (ii) monitoring environmental health and risks of governmental policies, (iii) legislating biodiversity conservation through wetland management, and (iv) enhancing the productivity of natural and agricultural ecosystems. This is especially true for Shaanxi Province and Xinjiang Uygur Autonomy, given that both have encountered large ecological deficits, indicating a rapid environmental deterioration in these two provinces.

At a broad scale, the region was on a relatively sustainable development route, but the provincial- and county-scale revealed huge spatial heterogeneity. Innovative eco-economy and sustainable development strategies should be made not only based on the gap between the supply and demand of the biocapacity in a region, but also based on the spatial heterogeneity of the biocapacity derived here at multiple spatial scales. Policy making should be based on information with detailed spatial heterogeneity. The Great Western Development Strategy of China as a long-term national policy has to recognize such spatial heterogeneity of biocapacity supply and resources to make more specific measures for the regional sustainable development at multiple spatial scales. Because the spatial structure of biocapacity largely relies on the geographical characteristics and land use, the biocapacity will inevitably change along with the availability of land and natural resources. Luck et al. (2001) also underscore the importance of incorporating spatial heterogeneity and data from multiple scales in the calculation of ecological footprint. For instance, in a similar study of the ecological footprint in Siena (Italy) at three different scales (provincial, district and commune), Bagliani et al. (2008) report the spatial heterogeneity of ecological footprint and biocapacity, and further suggest the necessity of considering ecological deficit and surplus spatially explicitly in urban planning. Similarly, the maps generated using the high-resolution land use image thus captured the essence of the spatially heterogeneous biocapacity in NWC, upon which the central and local governments should make policies for environmental conservation and sustainable development to mitigate the degradation of the environment in the region.

Human population density is an important determinant of the intensity of biocapacity supply, as measured by the per-unit-area biocapacity (Fig. 2). The robust power law relationship at the county level implies that the EF methodology of the biocapacity calculation is human-centred and reflects the intensity of exploitation of the local ecosystem by humans. However, the existence of a saturation level of the biocapacity suggests that future development should keep the eco-footprint below $5 \mathrm{gha} / \mathrm{ha}$ level to avoid the degradation of local ecosystems or high dependence on biocapacity import. In addition, this power law could also indicate the coupled relationship between humans and nature; that is, humans tend to dwell in places that can provide high biocapacity, which has been reported in numerous parallel studies regarding the preference of humans and animals to areas with high productivity (e.g., Luck, 2007).

Both the per-unit-area and per-capita biocapacity are critical indices for reflecting the intensity of the biocapacity. However, the per-capita biocapacity is generally inefficient to capture the real picture of biologically productive land in a given region due to its sensitivity to population dynamics. For instance, Qinghai's per-capita biocapacity was 2.37 times higher than that of Shaanxi, not because the land in Qinghai had a high biological productivity, but a reflection of its extremely low population density (1/25th of Shaanxi). Instead, the biological productivity of the land should be measured by the per- 
unit-area biocapacity. Although the per-unit-area biocapacity reflects the real carrying capacity of biologically productive land, it also varies with the change of land use yield and types. Therefore, the two indices should be used complimentarily.

The spatial unevenness of the biocapacity distribution is a universal and objective phenomenon. The analysis of its spatial distribution at coarse scales inevitably overlooks the inner characteristics of biocapacity, which can only be reflected at fine scales. The scaling pattern of biocapacity could encounter the modifiable areal unit problem as in landscape geography (Openshaw, 1984; Hui et al., 2010), and merits further attention on the specific spatial structure and partition of its distribution (e.g., using self-similarity technique; Hui and McGeoch, 2008).

The GIS-based calculation of the biocapacity using remote-sensing data of land use proved to be time-efficient and resulted in high resolution information, compared to using social statistic data alone. Furthermore, we have previously calculated the per capita biocapacity of Gansu in 2000 (=1.088 gha per capita) using social statistics data according to the standard EF methodology (Yue et al., 2006), with the estimation lower than 1.504 gha per capita obtained here (Table 2). This implies that the biocapacity calculated using social statistics alone could potentially underestimate the value of biocapacity (Chang and Xiong, 2005).

The eco-footprint and biocapacity showed large discrepancies at different scales, indicating an overall sustainable development in NWC, but large ecological deficits at provincial and county levels for specific areas. Although our revised method of using remote-sensing data in GIS for calculating the spatial heterogeneity of biocapacity can represent an efficient tool for overcoming the limitations of the conventional EF methodology, the analytic results were still not precise enough to obtain a full picture of the balancing mechanism of the biocapacity and eco-footprint, especially given that the ecofootprint was limited by low resolution statistics. Furthermore, McDonald and Patterson (2004) have demonstrated that Auckland's ecological footprint is not only originated from international trade but also regional trade with other regions in New Zealand and thus call for a process-based methodology for estimating regional ecological footprint. Luck et al. (2001) also advocate the necessity of incorporating ecosystem processes in the calculation of ecological footprint. A process-based methodology could provide a better capacity for forecasting future trends and elucidating the source-sink dynamics of EF components. Therefore, future investigations should place emphasis on (i) the spatial representations of eco-footprint and ecological budget at high-resolution, (ii) a spatially explicit prioritization of the $12 \%$ biologically productive area assigned for biodiversity conservation (e.g., Roura-Pascual et al., 2010), as well as (iii) the import/export dynamics associated with the ecological budget.

\section{Acknowledgements}

This work was supported by the National Natural Science Foundation of China (Nos. 40671179, 70873053 and 40721061), the Program for New Century Excellent Talents in University (NECT-090449), the National Social Science Foundation of China (Nos. 07XTQ004 and 06XJY004), the National Key Technology R\&D Program of China (No. 2007BAC03A11-02), The National Basic Research Program of China (No.2009CB421308), and the Chinese 111 program of the Ministry of Education. We are grateful to B. Laniewski and Tom Dijkstra for their constructive comments and kind help with the English wording of this manuscript, anonymous reviewers and the editor for constructive comments and suggestions.

\section{References}

Arrow, K., Bolin, B., Costanza, R., et al., 1995. Economic growth, carrying capacity, and the environment. Science 268 (5210), 520-521.
Bagliani, M., Gallic, A., Niccoluccic, V., et al., 2008. Ecological footprint analysis applied to a sub-national area: the case of the Province of Siena (Italy). Journal of Environmental Management 86, 354-364.

Bicknell, K.B., Ball, R.J., Cullen, R., et al., 1998. New methodology for the ecological footprint with an application to the New Zealand economy. Ecological Economics 27, 149-160.

Carey, D.I., 1993. Development based on carrying capacity: a strategy for environmental protection. Global Environmental Change 3 (2), 140-148.

Chang, B., Xiong, L., 2005. Ecological footprint analysis based on RS and GIS in arid land. J Geog Sci 15 (1), 44-52.

Costanza, R., 2000. The dynamics of the ecological footprint concept. Ecological Economics 32, 341-345.

Erb, K.H., 2004. Actual land demand of Austria 1926-2000: a variation on ecological footprint assessments. Land Use Policy 21, 247-259.

Gao, J.X., 2001. Exploration of sustainable development theory - theories and application of ecological carrying capacity. Chinese Environmental Science Press, Beijing (in Chinese).

Haberl, H., Erb, K.H., Krausmann, F., 2001. How to calculate and interpret ecological footprint for long periods of time: the case of Austria 1926-1995. Ecological Economics 38, 25-45.

Hansen, M., DeFries, R., Townshend, J.R.G., et al., 2000. Global land cover classification at $1 \mathrm{~km}$ spatial resolution using a classification tree approach. International Journal of Remote Sensing 21, 1331-1364.

Heumann, B., Moran, D., 2006. Mapping the Ecological Footprint of International Trade. McGill University, Interdisciplinary Graduate Student Research Symposium.

Hui, C., McGeoch, M.A., 2008. Does the self-similar species distribution model lead to unrealistic predictions? Ecology 89, 2946-2952.

Hui, C., Veldtman, R., McGeoch, M.A., 2010. Measures, perceptions and scaling patterns of aggregated species distributions. Ecography 33, 95-102.

Jenerette, G.D., Marussich, W.A., Newell, J.P., 2006. Linking ecological footprints with ecosystem valuation in the provisioning of urban freshwater. Ecological Economics $59,38-47$

Kissinger, M., Fix, J., Rees, W.E., 2007. Wood and non-wood pulp production: comparative ecological footprinting on the Canadian prairies. Ecological Economics $62,552-558$

Kissinger, M., Rees, W.E., 2009. Footprints on the prairies: degradation and sustainability of Canadian agriculture in a globalizing world. Ecological Economics 68, 2309-2315

Kissinger, M., Rees, W.E., 2010. Importing terrestrial biocapacity: the U.S. case and global implications. Land Use Policy 27, 589-599.

Kitzes, J., Wackernagel, M., Loh, J., et al., 2008. Shrink and share: humanity's present and future ecological footprint. Phil Trans R Soc Lond B Biol Sci 363 (1491), 467-475.

Kitzes, J., Galli, A., Bagliani, M., et al., 2009. A research agenda for improving national ecological footprint accounts. Ecological Economics 68, 1991-2007.

Levett, R., 1998. Footprinting: a great step forward, but tread carefully. Local Environment 3 (1), 67-74.

Lenzen, M., Murray, S., 2001. A modified ecological footprint method and its application to Australia. Ecological Economics 37, 229-255.

Lieth, H., 1972. Modeling the primary productivity of the world. Nature and Resources 8 (2), 5-10.

Liu, J.Y., Zhang, D.F., Luo, D., et al., 2002. Land-cover classification of China: integrated analysis of AVHRR imagery and geophysical data. International Journal of Remote Sensing 24, 2485-2500.

Luck, M.A., Jenerette, G.D., Wu, J., et al., 2001. The urban funnel model and the spatially heterogeneous ecological footprint. Ecosystems 4, 782-796.

Luck, G.M., 2007. The relationships between net primary productivity, human population density and species conservation. Journal of Biogeography 34,201-212.

Mayer, A.L., 2008. Strengths and weaknesses of common sustainability indices for multidimensional systems. Environment International 34, 277-291.

McDonald, G.W., Patterson, M.G., 2004. Ecological footprints and interdependencies of New Zealand regions. Ecological Economics 50, 49-67.

Monfreda, C., Wackernagel, M., Peumling, D., 2004. Establishing national capital accounts based on detailed ecological footprint and biological capacity assessments. Land Use Policy 21, 231-246.

Moran, D., Wackernagel, M., Kitzes, J., et al., 2009. Trading spaces: calculating embodied ecological footprints in international trade using a Product Land Use Matrix (PLUM). Ecological Economics 68, 1938-1951.

Odum, H.T., 1996. Environmental Accounting: Emergy and Environmental Decision Making. John Wiley and Sons, New York.

Openshaw, S., 1984. The Modifiable Areal Unit Problem. Geo Books, Norwick.

Opschoor, H., 2000. The ecological footprint: measuring rod or metaphor? Ecological Economics 32, 363-365.

Rees, W.E., 1992. Ecological footprint and appropriated carrying capacity: what urban economics leaves out. Environ Urbanization 4, 121-130.

Rees, W.E., Wackernagel, M., 1994. Ecological footprints and appropriated carrying capacity: measuring the natural capital requirements of the human economy. In: Jansson, A.M., Hammer, M., Folke, C., Costanza, R. (Eds.), Investing in Natural Capital: The Ecological Economics Approach to Sustainability. Island Press, Washington DC, pp. 362-390.

Rees, W.E., 2000. Eco-footprint analysis: merits and brickbats. Ecological Economics 32 (3), 371-374

Rees, W.E., 2006. Ecological footprints and bio-capacity: essential elements in sustainability assessment. In: Dewulf, J., Van Langenhove, H. (Eds.), Renewables-Based Technology: Sustainability Assessment. John Wiley and Sons, Chichester, pp. 143-158.

Roura-Pascual, N., Krug, R.M., Richardson, D.M., Hui, C., 2010. Spatially-explicit sensitivity analysis for conservation management: exploring the influence of 
decisions in invasive alien plant management. Diversity and Distributions 16 , 426-438.

Sagoff, M., 1995. Carrying capacity and ecological economics. Bioscience 45 (9), 610-620.

Scoones, I., 1993. Economic and ecological carrying capacity: applications to pastoral systems in Zimbabwe. In: Barbier, E.B. (Ed.), Economics and Ecology: New Frontiers and Sustainable Development. Chapman \& Hall, London, pp. 96-117.

Seidl, I., Tisdell, C.A., 1999. Carrying capacity reconsidered: from Malthus' population theory to cultural carrying capacityal. Ecological Economics 31 (3), 395-408.

Senbel, M., McDaniels, T., Dowlatabadi, H., 2003. The ecological footprint: a nonmonetary metric of human consumption applied to North America. Global Environmental Change 13, 83-100.

Templet, P.H., 2000. Externalities, subsidies, and the ecological footprint: an empirical analysis. Ecological Economics 32 (3), 381-383.

van den Bergh, J.C.J.M., Verbruggen, H., 1999. Spatial sustainability, trade and indicators: an evaluation of the "ecological footprint". Ecological Economics 29 (1), 61-72.

van Vuuren, D., Smeets, E.M.W., 2000. The ecological footprint of Benin, Bhutan, Costa Rica and the Netherlands. Ecological Economics 34 (2), 115-130.

Wackernagel, M., Rees, W.E., 1996. Our Ecological Footprint. New Society Publishers, Philadelphia, Reducing Human Impact on The Earth.

Wackernagel, M., Galli, A., 2007. An overview on ecological footprint and sustainable development: a chat with Mathis Wackernagel. International Journal of Ecodynamics 2 (1), 1-9.

Wackernagel, M., Onisto, L., Bello, P., et al., 1999. National natural capital accounting with the ecological footprint concept. Ecological Economics 29 (3), 375-390.

Wackernagel, M., Silverstein, J., 2000. Big things first: focusing on the scale imperative with the ecological footprint. Ecological Economics 32 (3), 391-394.

Wackernagel, M. Schulz, N.B., Deumling, D., et al., 2002. Tracking the ecological overshoot of the human economy. Proceedings of the National Academy of Sciences 99 (14), 9266-9271.
Wackernagel, M., Yount, J.D., 2002. Footprint for sustainability: the next step. Environment, Development and Sustainablitiy 2, 21-42.

Wang, S.Y., Liu, J.Y., Zhang, Z.X., et al., 2001. Analysis on spatial-temperal features of land use in China. Acta Geographica Sinica 56 (6), 631-639 (in Chinese).

WCED (World Commission on Environment and Development), 1987. Our Common Future. Oxford University Press, Oxford, p. 383.

White, T.J., 2007. Sharing resources: the global distribution of the ecological footprint Ecological Economics 64 (2), 402-410.

Wood, G., 2003. Modelling the ecological footprint of green travel plans using GIS and network analysis: from metaphor to management tool? Environment and Planning B: Planning and Design 30, 523-540.

WWF (World Wide Fund for Nature) International, ZSL (Zoological Society of London), and Global Footprint Network, 2004. Living Planet Report 2004. WWF. Gland, Switzerland (http://wwf.panda.org/about_our_earth/all_publications/living_planet_report/ living planet_report timeline/).

WWF (World Wide Fund for Nature) International, ZSL (Zoological Society of London), and Global Footprint Network, 2006. Living Planet Report 2006. WWF. Gland, Switzerland (http://wwf.panda.org/about_our_earth/all_publications/living_planet_report/ living planet report timeline/).

WWF (World Wide Fund for Nature) International, ZSL (Zoological Society of London), and Global Footprint Network, 2008. Living Planet Report 2008. WWF. Gland, Switzerland (www.panda.org/livingplanet).

Yue, D., Xu, X., Li, Z., et al., 2006. Spatiotemporal analysis of ecological footprint and biological capacity of Gansu, China 1991-2015: down from the environmental cliff. Ecological Economics 58, 393-406.

Zhang, G.P., Liu, J.Y., Zang, Z.X., et al., 2002. Remote sensing based analysis of the distribution pattern and dynamic changes of sandy land in China from 1995 to 2000. Acta Ecologica Sinica 22 (9), 1500-1506 (in Chinese). 